\title{
Space Shuttle Strategic Planning Status
}

\author{
Gordon L. Norbraten and Edward M. Henderson \\ NASA Johnson Space Center, Houston, TX
}

\begin{abstract}
The Space Shuttle Program is aggressively planning the Space Shuttle manifest for assembling the International Space Station and servicing the Hubble Space Telescope. Implementing this flight manifest while concurrently transitioning to the Exploration architecture creates formidable challenges; the most notable of which is retaining critical skills within the Shuttle Program workforce. The Program must define a strategy that will allow safe and efficient fly-out of the Shuttle, while smoothly transitioning Shuttle assets (both human and facility) to support early flight demonstrations required in the development of NASA's Crew Exploration Vehicle (CEV) and Crew and Cargo Launch Vehicles (CLV). The Program must accomplish all of this while maintaining the current level of resources. Therefore, it will be necessary to initiate major changes in operations and contracting. Overcoming these challenges will be essential for NASA to fly the Shuttle safely, accomplish the President's "Vision for Space Exploration," and ultimately meet the national goal of maintaining a robust space program. This paper will address the Space
\end{abstract}

Shuttle Program's strategy and its current status in meeting these challenges.

\section{Introduction}

The Space Shuttle Program's Strategic Planning for the Transition and Retirement (T\&R) of the Space Shuttle has begun. Human space flight transition plans have been drafted and transition control boards have been established to expedite change requests. A strategic capability assessment is in progress to define all Space Shuttle assets and their last need dates. Work force sensitivity models are being developed. Constellation Program needs are being identified and transition schedules are under negotiation.

The T\&R start-up activity and discussions on terminating Shuttle contracts and closing facilities has emphasized how significantly these decisions impact any future redirection that may be required from unknowns. Cost and schedules for restarting activity after shutdown will have considerable increases and delays. Therefore, it is timely to do some contingency planning. This paper addresses alternative plans that could help mitigate the impacts should changes be required in the future.

The National Aeronautics and Space Administration has begun significant activity toward implementing the Vision for Space Exploration; returning to the Moon (Fig. 1) and sending humans to Mars and beyond. The Space Shuttle is returning to flight to complete assembly of the International Space Station (ISS) and the newly organized Constellation Program $(\mathrm{Cx})$ is proceeding toward a Systems Requirements Review in order to baseline their space

American Institute of Aeronautics and Astronautics 
transportation architecture (Figs $2 \& 3$ ).

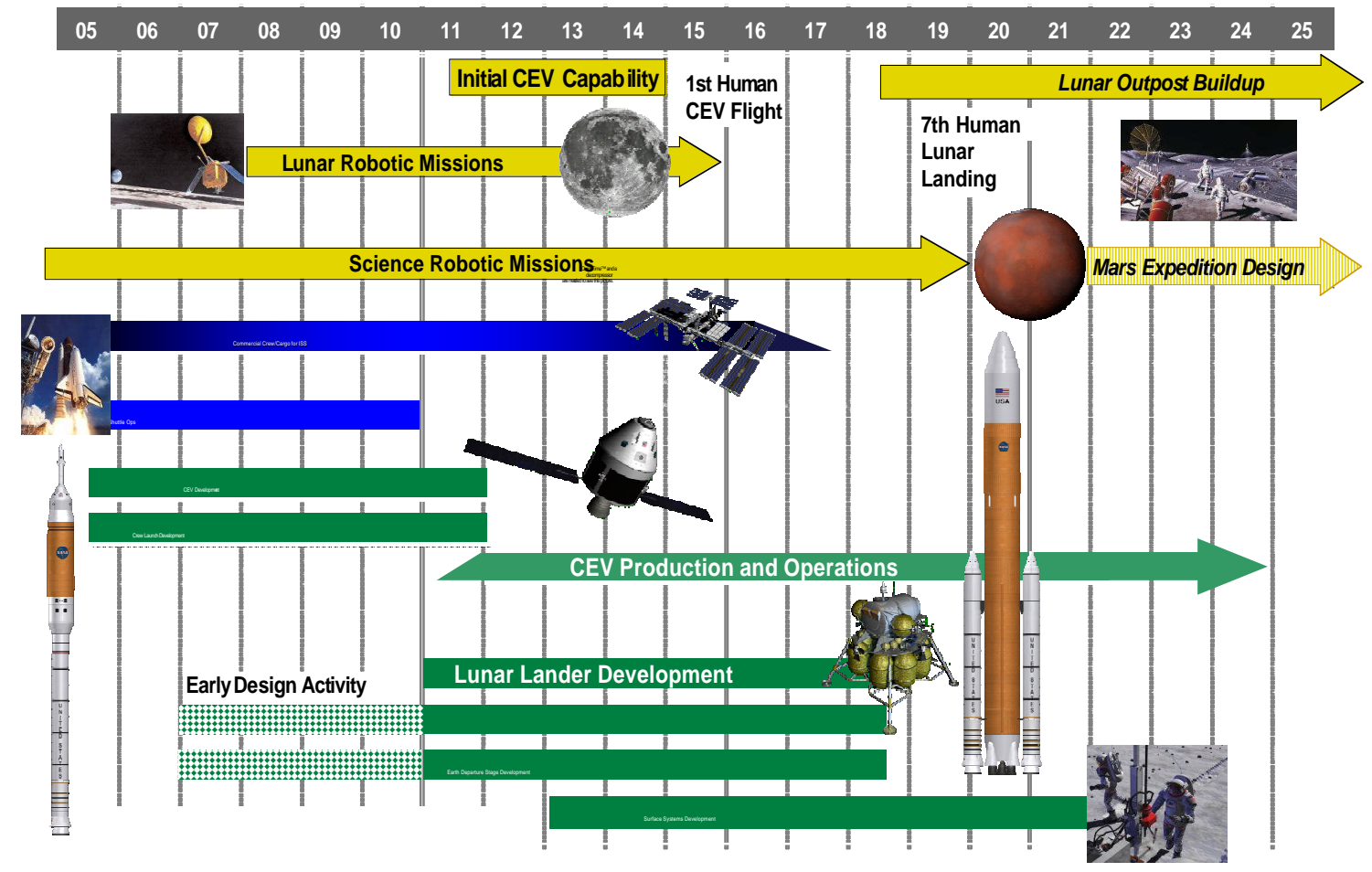

Figure 1. NASA's Exploration Roadmap

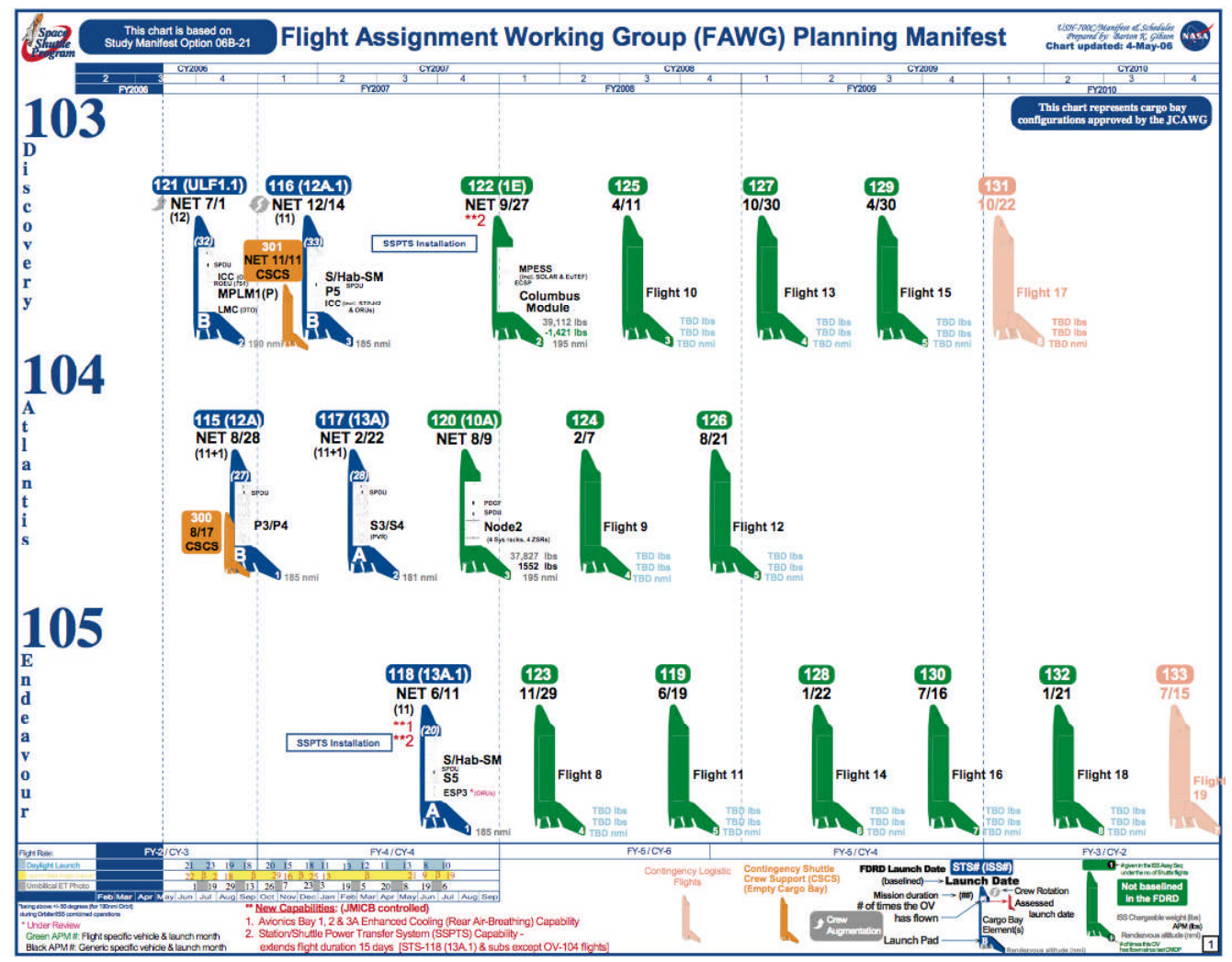

Figure 2. Shuttle Manifest

American Institute of Aeronautics and Astronautics 


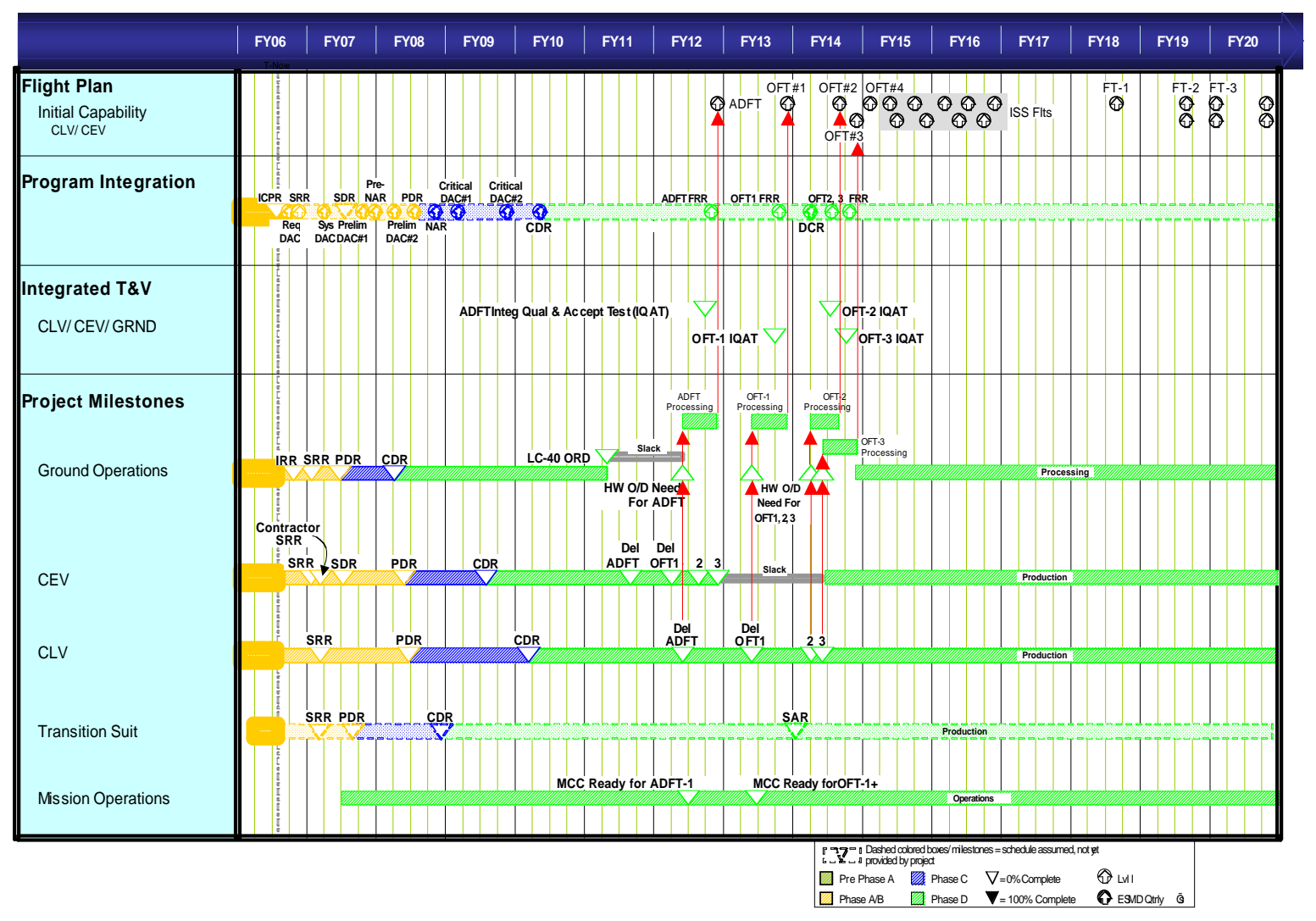

Figure 3. Constellation Program - IMS (Initial Capability)

The return of humans to the Moon no later than 2020 is a high priority for America's Space Program. Meeting this goal will require near-term progress in four areas.

1) Proof of design concepts of the $\mathrm{Cx}$ space transportation architecture through early demonstrations of its essential elements.

2) Closure of the gap between the last Shuttle flight and the first manned Crew Launch Vehicle flight.

3) Completion of ISS assembly in order to honor America's commitment to its international partners and to finish the platform needed to demonstrate capabilities for taking humans to the Moon and Mars.

4) Timely transition of Shuttle assets that will allow Cx to benefit from the Shuttle program technologies and capabilities.

It is crucial for these events to be successful for the Agency's mission to survive and for America to retain its status as a leader in Space. However, success is not guaranteed. Major demands on the budget, complexities associated with completing the flight manifest needed to assemble the ISS, and the uncertainties of Constellation Program's requirements for the performance and schedule of crew and cargo launch vehicles compound to add significant risks to success. In addition, decisions are being made this year to close out Shuttle contracts and shut down supply chains without a full understanding of $\mathrm{Cx}$ requirements for those capabilities and assets (Fig.4). Restarting suppliers and supply chains is expensive and time consuming, thus threatening to our exploration schedule.

American Institute of Aeronautics and Astronautics 


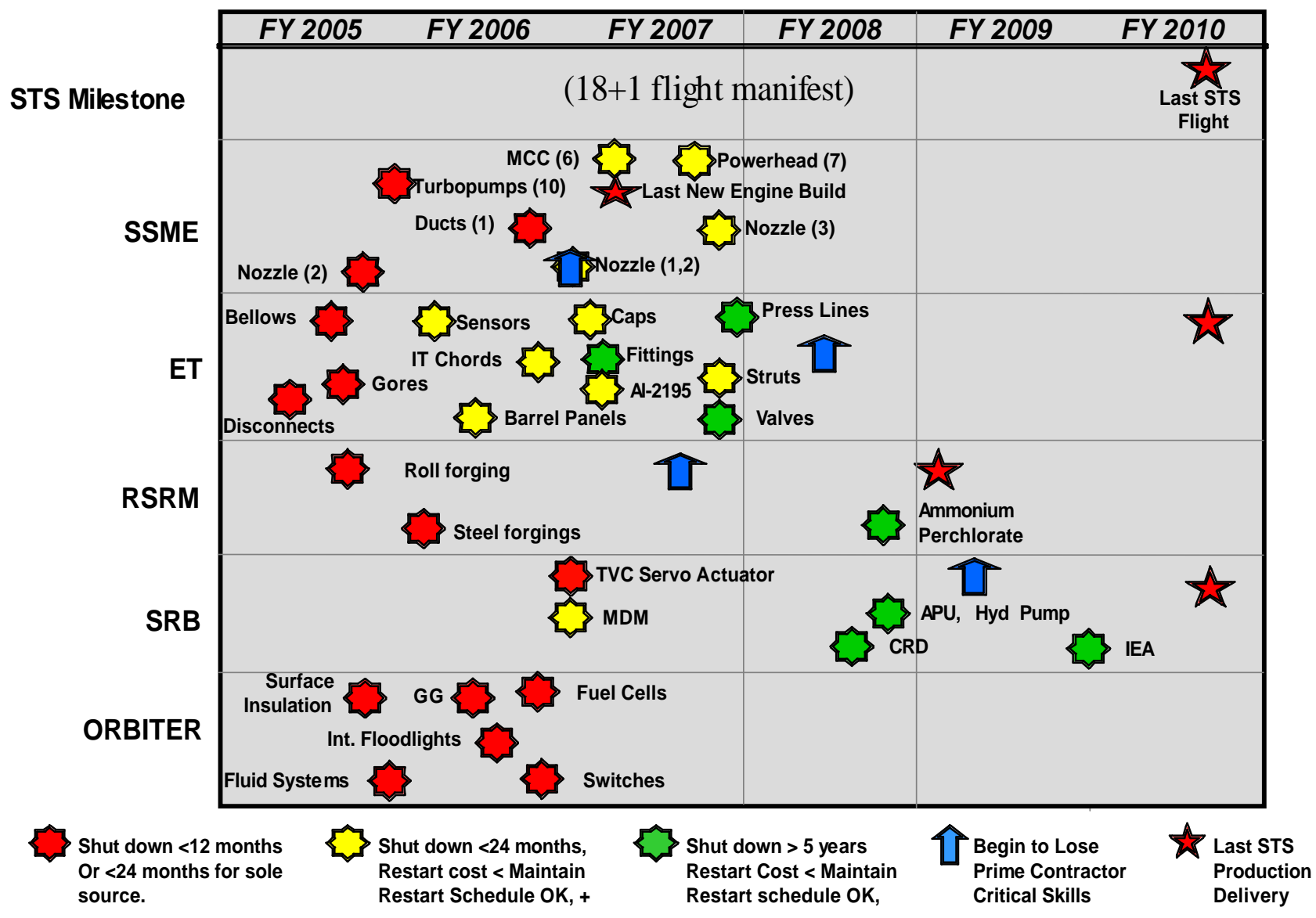

Figure 4. Key Manufacturing Decision Dates

For the reasons outlined above, it is both prudent and practical to keep space transportation architecture options open until more certainty exists in program plans. The purpose of this issue paper is to offer an assessment of alternatives should the Space Shuttle and/or the Constellation vehicles prove unsuccessful in meeting performance, budget or schedule requirements.

\section{Assessment of Alternatives}

The threats against the current Shuttle and Constellation plans warrant consideration of contingencies. In developing these contingencies, a representative suite of crew and cargo launch vehicle systems were assessed as alternatives. Within the matrix (Fig. 5), column 1 is the baseline Constellation architecture and the other columns represent alternative launch configurations. All use Shuttle derived elements except columns 5 and 6, which consider EELV options. The last column (7) is an unmanned Shuttle option considered for ISS assembly. 


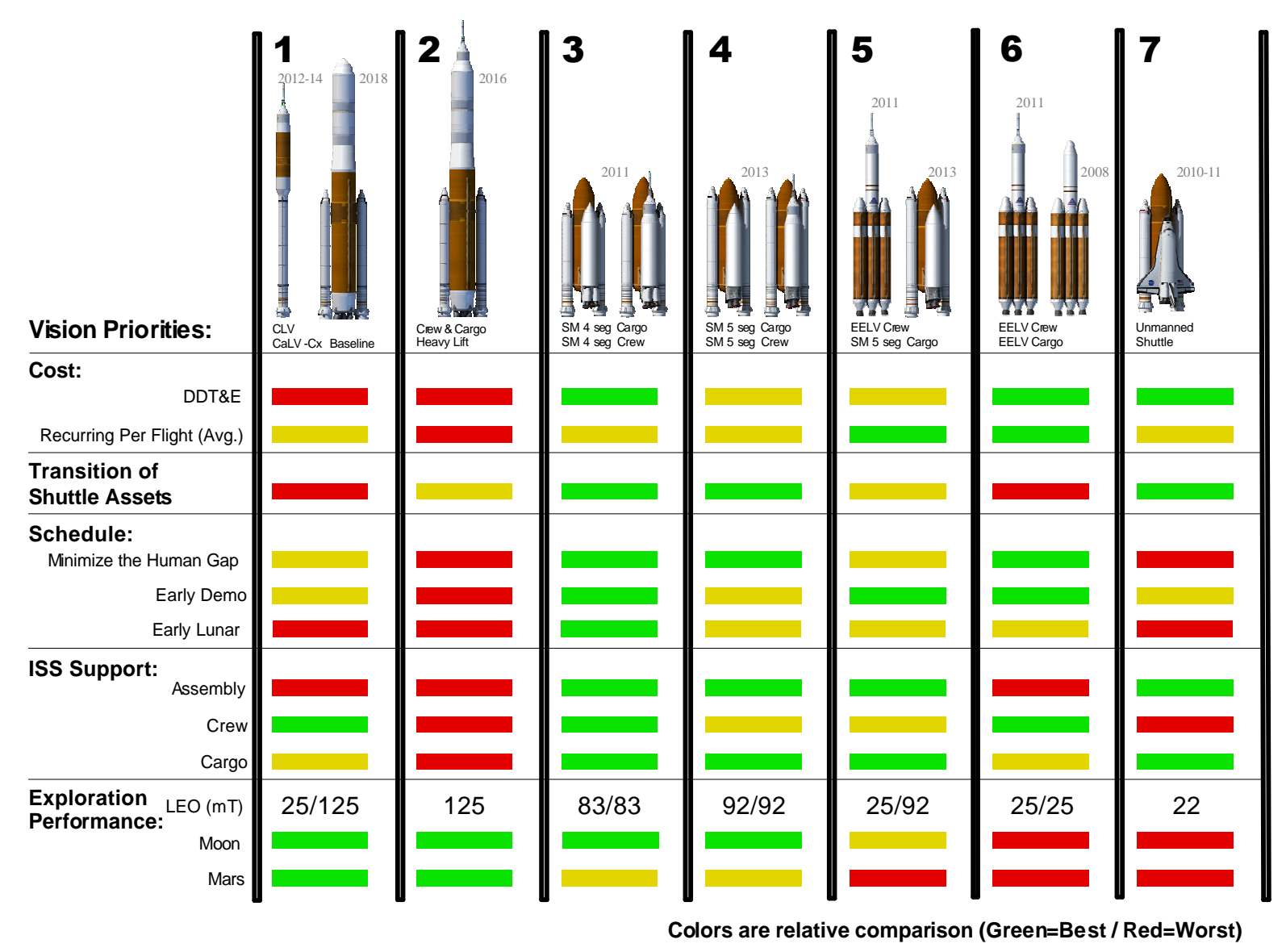

Figure 5. Shuttle Derived Launch Vehicles Assessment Matrix

Each alternative system was assessed for: development and recurring costs; highest potential for transition of Shuttle assets; the best schedule for providing early demonstrations, shortest gap in assured hum an access to space; ability to support ISS assembly and logistics; and meeting performance requirements needed for exploration. Colors are used to show how each option relates to the other in meeting the assessed priority: GREEN is the best, RED is the worst and YELLOW is in between.

\section{Scenarios}

With the assessment of the space transportation vehicle systems complete, the next step is to run through the two most likely scenarios that would require a contingency plan.

Two likely scenarios are discussed below:

\section{A. Shuttle Cannot Complete the Manifest}

The first scenario, not being able to complete the remaining Shuttle flight manifest, will have a major impact on NASA's ability to achieve final assembly of the ISS. The degree of impact largely depends on when in the remaining assembly sequence the Shuttle flights are terminated. If there is still a significant amount of ISS hardware to be delivered for assembly, then an alternate delivery capability would be needed.

1a) The ISS assembly elements were designed for the Shuttle launch environment. Therefore launching close to the Shuttle loads profile avoids any ISS element redesign for different ascent loads, as would be required if foreign or new launch vehicles were used to complete assembly. The best near term match would be an unmanned Shuttle. It could be available sooner than a new launch vehicle and its payload performance would be better with no crew

American Institute of Aeronautics and Astronautics 
than the existing Shuttle.

This capability has been evaluated several times in the past. The unmanned Shuttle would require an Autonomous Rendezvous and Docking (AR\&D) capability and automation of the Shuttle flight sequence. Based on a Shuttle Life Extension Program (SLEP) conference study, adding these capabilities would take two to three years to develop and cost approximately $\$ 300 \mathrm{M}$. Though the unmanned Shuttle would be the best alternative option to complete ISS assembly, it would not directly support a lunar mission. It could, however, compliment a side mount Shuttle architecture that would be ready for a lunar mission sooner than the $\mathrm{Cx}$ architecture.

1b) An alternate approach for assembling the ISS is going directly to a Shuttle derived side mount cargo launch vehicle (SDLV) capability with AR\&D. This would take longer to develop, 4 to 5 years, and cost more ( $\$ 5 B)$ than the unmanned Shuttle. However, it would more than double the amount of cargo carried to station for a single launch and it would meet the performance required for conducting a human lunar mission.

Both of the previous assembly options would require an alternate means for getting the crew to the space station to support near term assembly. Getting the crew to the ISS can be accomplished either by flying one or two manned Shuttle launches a year, with the Soyuz, or with the new Crew Exploration Vehicle (CEV) when it becomes available.

1c) The new Constellation heavy lift cargo launch vehicle (CaLV) would have more than enough performance to support station assembly but based on current schedule projections, it would not be available in time.

\section{B. 2. Constellation Architecture Does Not Meet Expectations}

The second scenario considered is the inability of the Constellation space transportation architecture to meet the performance, budget or schedule requirements for a timely lunar return. Currently, the planned architecture for launching the lunar exploration elements consists of two launch vehicles, the Crew Launch Vehicle (CLV) used to launch the CEV and a Cargo Launch Vehicle (CaLV) used to launch the Earth Departure Stage (EDS) and the Lunar Surface Access Module (LSAM). The CLV is scheduled to be operational no later than 2014 with a challenge to launch earlier in order to minimize the gap after the last Shuttle launch in 2010. The CaLV is required for a lunar mission scheduled for 2020. The Constellation Program, however, is targeting a lunar launch as early as 2018. At present, the largest concern about the system is with the ability of CLV to meet the performance required to launch the CEV. This is because there is little or no margin with the major design work still to be done. Should the CLV fail to meet expectations and short of reducing exploration capabilities of the $\mathrm{CEV}$, three architecture alternatives are addressed here:

1) Accelerate the planned CaLV development and use it to fly crew and/or cargo,

2) Human rate an Enhanced Expendable Launch Vehicle (EELV) or,

3) Add the CEV to the top of the cargo carrier on a side mount Shuttle derived launch vehicle (SDLV).

2a) Accelerating the CaLV would support the performance needed for a lunar mission and may allow a reduced mission to be accomplished in only one launch, similar to the Saturn V used in Apollo. Or it would allow a much more robust mission with two launches and rendezvous in low-Earth orbit. However, the schedule would be difficult to advance significantly, causing a very large gap in the country's human launch capability. Also, any CaLV schedule would be too late to support any ISS assembly activity. This option would also have the largest impact, thus cost, to ground operations and existing launch facilities.

2b) Human rating EELVs for crew transportation could be an attractive option depending on the difficulties encountered. This option would also support the Department of Defense (DoD) by using their launch vehicle and increasing their customer base. This benefit will outweigh the increased cost incurred by a human rating their launch vehicle. Unfortunately, the EELV would not have enough performance for lunar cargo flights without an excessive number of launches, on orbit assembly, and the associated large overhead. Therefore, a separate heavy lift cargo launch capability would still be required. In addition using DoD launch facilities would be an advantage for flying out the remaining Shuttle flights by eliminating any impact to existing Shuttle facilities. The bottom line is that EELVs could not augment ISS assembly, but could provide logistical support after the ISS is assembled.

American Institute of Aeronautics and Astronautics 


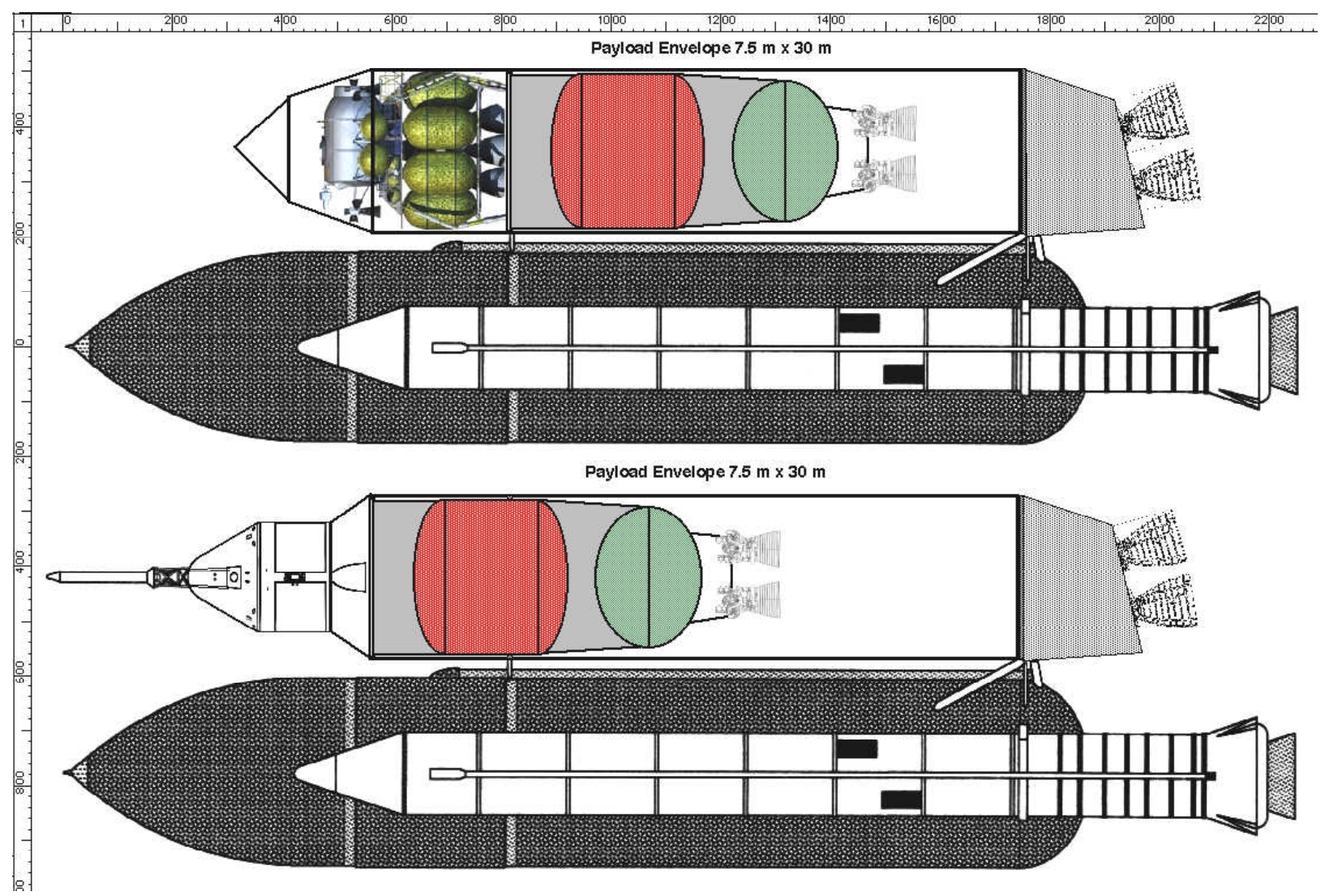

Figure 6. EDS Stage For Lunar Missions

2c) The side-mount Shuttle Derived Launch Vehicle (SDLV) would require adding the CEV to the top of the cargo carrier. This places the CEV far enough forward to avoid any significant debris concern. Launch aborts from this position will require further analysis to ensure acceptable crew safety exists (Fig. 6). However, it has several strong advantages:

1) It is more compatible with existing Shuttle facilities, hardware, vendors and skills and thus reduces operational development costs.

2) It has a demonstrated and proven capability that would be ready sooner than the other options.

3) It can support station assembly and crew rotation and most importantly for the Vision for Space Exploration, it is the fastest track to the Moon.

The side mount launch vehicle with the existing four-segment solid rocket boosters (SRB) could support a human lunar mission with two launches (Fig. 7). It provides the necessary performance for the ESAS LSAM and CEV architecture elements for a lunar mission. This attribute results from the additional performance $(\sim 14 \mathrm{mT})$ added by a suborbital staging launch profile (Fig. 8). The profile shown is for the LSAM element. A similar profile exists for the second launch involving the CEV. This new profile has a low MECO velocity $(M=17-20)$ for staging the Earth Departure Stage (EDS) to achieve orbit, while disposing the External Tank, cargo carrier and main propulsion engines in the mid Atlantic.

Note: different combinations of crew and cargo launch vehicles are feasible, eg. a CLV for crew and heavy lift SDLV for cargo or an EELV for crew and a SDLV for cargo. However, these would increase the number of launches needed for a lunar mission. 
Foreign launch vehicles were not considered in this assessment.

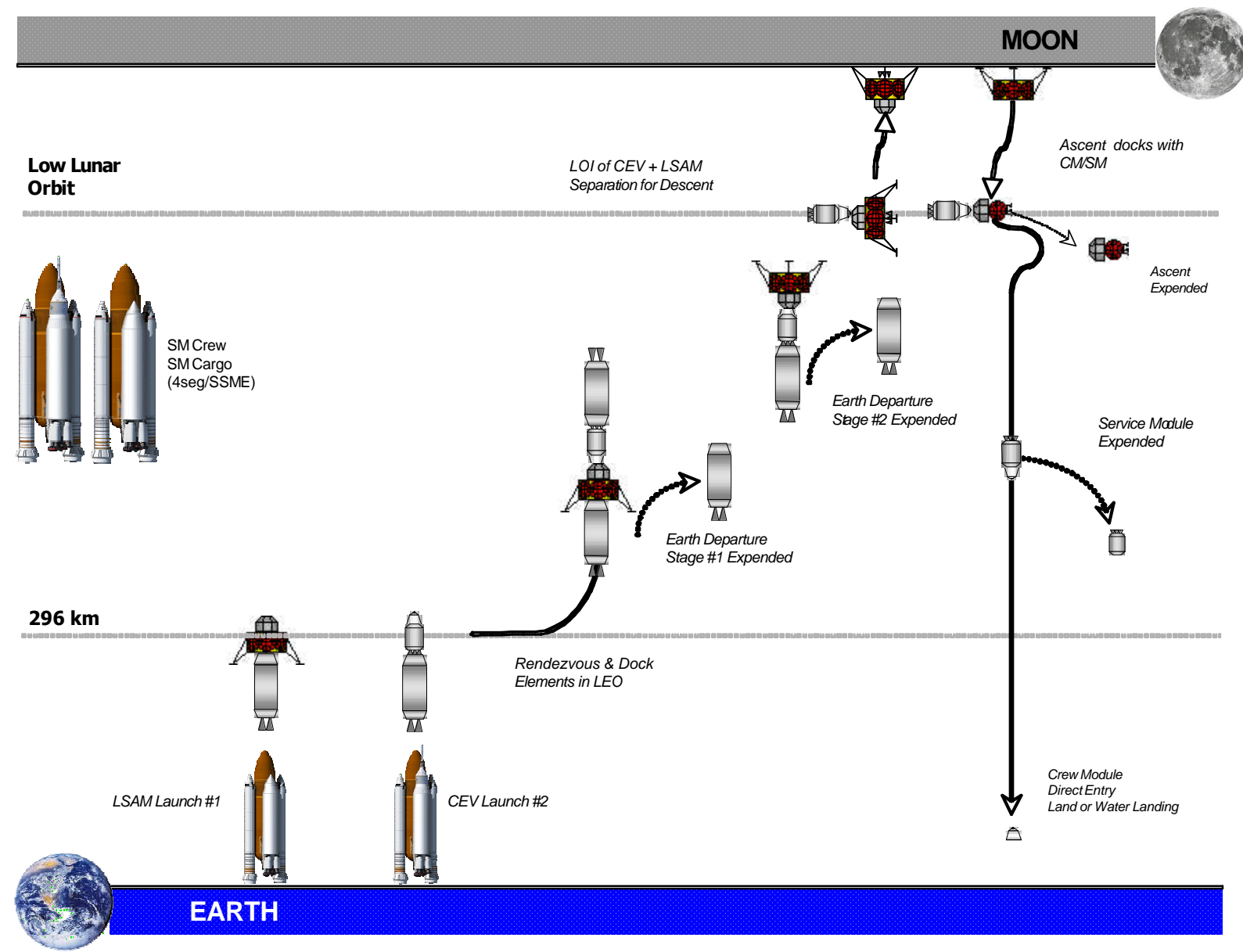

Figure 7. Series Mission - Earth Orbit Rendezvous

ESAS LSAM \& CEV

\section{Common Elements}

A SDLV is a common option for most contingencies and has the least impact to the existing Shuttle infrastructure. It supports both scenarios discussed and gets the U. S. to the Moon the soonest- prior to 2015. Independently it has a large performance capability, 83 to $92 \mathrm{mT}$ to low Earth orbit, and it could also meet a variety of needs for unknown future requirements. A new five segment booster (FSB) could be added later for even more performance, increasing margins and capabilities for enhanced lunar missions and could possibly support a Mars mission. Also, the development costs have high fidelity, are reasonable and could potentially save money over the current architecture, if that becomes a need. Other benefits are that a SDLV could make maximum use of spare Shuttle hardware and existing test facilities. Also, the required workforce competencies and skills are compatible with ongoing Space Shuttle support and work at other NASA centers. 


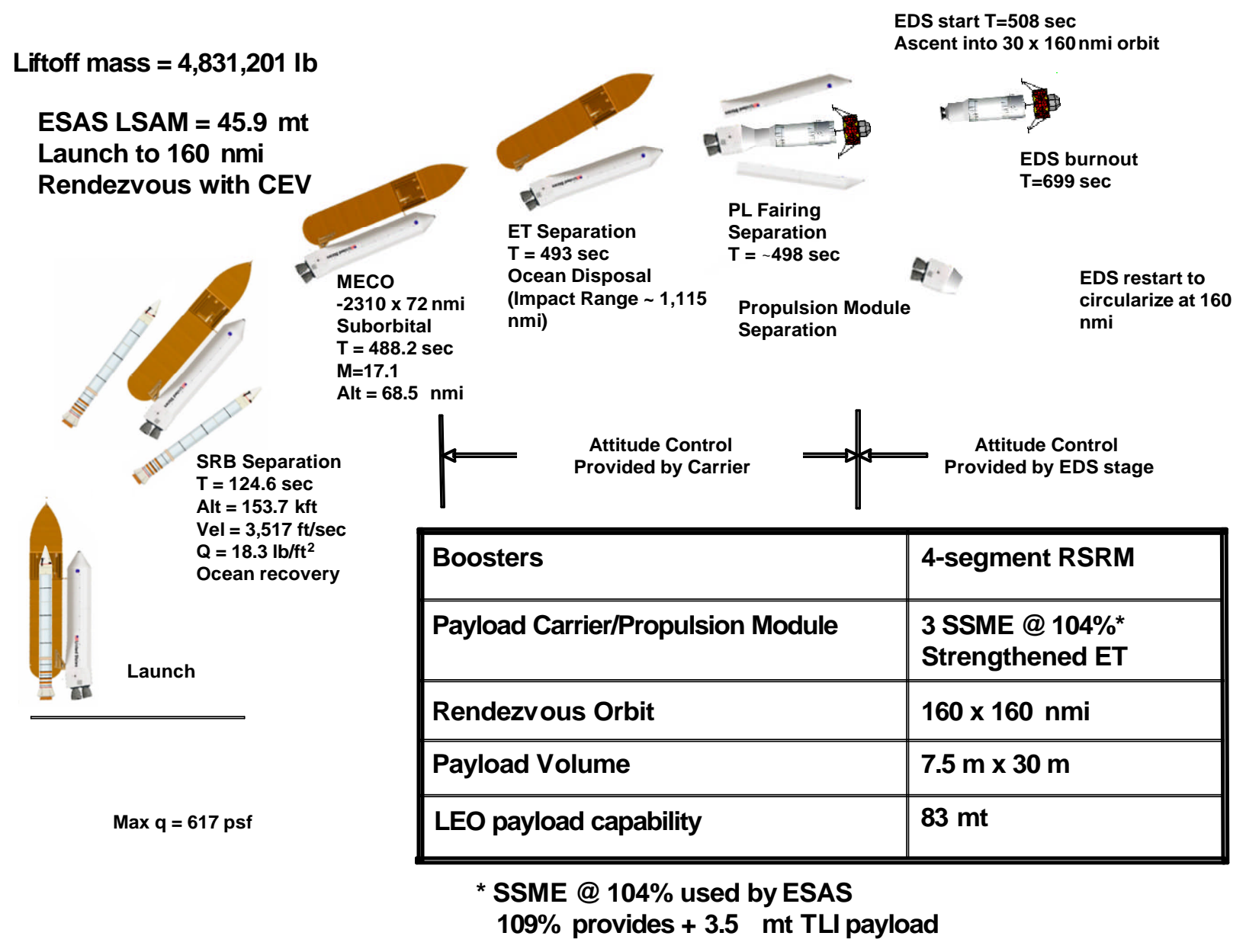

Figure 8. 4-seg Side-mount Heavy Lift Launch \#1 (LSAM+EDS) of Series TLI

\section{Conclusion and Recommendations}

This paper captures an assessment of alternatives. The best case scenario is to continue with the current plans for assembling the International Space Station and building the planned space vehicles needed to support the Constellation Program and the Vision for Space Exploration.. However, with the formable uncertainties in accomplishing this very ambitious plan, alternate architecture options should be ready to proceed immediately should insurmountable obstacles occur. The most rational program insurance would be to perform some low cost, low risk, parallel development that would allow a smooth transition to an alternate approach if or when needed. The most critical element common to the alternatives recommended is Autonomous Rendezvous \& Docking (AR\&D) which will ultimately be needed for the lunar mission, regardless of the need for contingency. AR\&D is the pacing item for an unmanned Shuttle capability and the side mount cargo launch vehicle. In addition, a cargo carrier design activity should be initiated immediately. This would facilitate a Shuttle derived heavy lift capability that would support station assembly, early lunar flights and would allow later development of the heavy-lift capabilities needed for Mars. Lastly, the Shuttle supply lines needed to support these options should remain solvent. 
American Institute of Aeronautics and Astronautics 